\title{
RUPTURED OVARIAN ECTOPIC - A CASE REPORT
}

\author{
Irfana S1, Bhuvana S2 , Jaya Vijayaraghavan ${ }^{3}$, Sarah Kuruvilla4 ${ }^{4}$, Shanmuga Priya ${ }^{5}$
}

\section{HOW TO CITE THIS ARTICLE:}

Irfana S, Bhuvana S, Jaya Vijayaraghavan, Sarah Kuruvilla, Shanmuga Priya. "Ruptured ovarian ectopic - a case report”. Journal of Evolution of Medical and Dental Sciences 2013; Vol2, Issue 39, September 30; Page: 7575-

7577.

ABSTRACT: Ovarian pregnancy is a rare form of ectopic pregnancy. It is often difficult to distinguish from tubal pregnancy, and diagnosis and management are frequently a challenge. This is a case report of a G2P1L1 with 5 weeks amenorrhoea presented to the emergency room with complaints of diffuse abdominal pain and spotting per vaginum. Based on the clinical and imaging studies, ruptured tubal ectopic pregnancy was suspected and emergency laparotomy done. Intra operative findings and histopathology confirmed ovarian ectopic gestation, was managed with salpingo oophorectomy.

INTRODUCTION: Ectopic pregnancy occurs when the developing blastocyst becomes implanted at a site other than the endometrium of the uterine cavity. The most common extra-uterine location is the fallopian tube, which accounts for 98 percent of all ectopic gestations ovarian pregnancy occurs approximately 0.5 to 3 percent of ectopic pregnancies $(1,2)$. Histopathological criteria are used to distinguish ovarian pregnancies from those originating in the fallopian tube.

CASE REPORT: Mrs. X, G2P1L1, previous normal delivery with 5 weeks of amenorrhoea, presented to the emergency room with complaints of pain abdomen, diffuse in nature and spotting per vaginum. She reported of regular menstrual cycles, no use of intrauterine contraceptive device, no history of pelvic inflammatory disease, or any gynaecological surgery. On initial examination she was found to be pale, her blood pressure was $80 / 40 \mathrm{~mm} \mathrm{Hg}$, pulse rate was 112 / min. On palpation, there was diffuse abdominal tenderness and guarding. Bimanual examination revealed cervical motion tenderness and right adnexal tenderness, uterus was anteverted and of normal size. Urine pregnancy test was positive, serum beta HCG level was $4556 \mathrm{~m} \mathrm{IU} \mathrm{/} \mathrm{ml}$ and imaging revealed large hyperdense collection of $12 * 14^{*} 10 \mathrm{~cm}$ in the pelvis, located more on the right side, with the presence of free fluid in the pelvis and absence of intra uterine gestational sac, a diagnosis of ruptured ectopic was made. Her haemoglobin was found to be $4 \mathrm{~g} / \mathrm{dl}$. A decision for laparotomy was made based on haemoperitoneum and features of haemorrhagic shock. Intra operative findings revealed haemoperitoneum of around 1 litre including $800 \mathrm{cc}$ of clots, normal size uterus, right ovary was enlarged with mass of $3^{*} 2 \mathrm{~cm}$ with blood clot protruding from the surface, left ovary had features of corpus luteal cyst and both the tubes were normal. Right salpingo oophorectomy was done. The post operative period was uneventful and the patient was discharged 3 days later. Histopathology showed ovary with numerous chorionic villi in stroma, consistent with ovarian ectopic.

DISCUSSION: Ovarian pregnancy is a rare variant of ectopic pregnancy. In contrast to tubal pregnancy, a history of pelvic inflammatory disease or the use of an intrauterine contraceptive 
device does not increase the risk of ovarian pregnancy. Ovarian pregnancy appears to be a random event that is not associated with a history of infertility or recurrent extra-uterine pregnancy. Pre operative diagnosis of ovarian ectopic pose a challenge, the initial diagnosis is made only on the operating table and the final diagnosis is made by histological diagnosis. The cause of ovarian pregnancy is not clear, however hypotheses have suggested interference in the release of the ovum from the ruptured follicle, malfunction of the tubes and inflammatory thickening of the tunica albuginea can lead to ovarian pregnancy(3). Ectopic pregnancy should be suspected in any women of reproductive age with symptoms of abdominal pain, amenorrhoea and vaginal bleeding; especially those who have risk factors for an extrauterine pregnancy. The diagnosis of ovarian pregnancy is typically made at the time of surgery, but differentiation from a hemorrhagic ovarian cyst or pregnancy in the distal fallopian tube can be difficult. Ultrasound may suggest the diagnosis preoperatively (4). The diagnosis is usually made clinically, based upon results of the imaging studies (ultrasound) and laboratory tests, serum beta HCG $(5,6)$. Spigelberg criteria is essential for the diagnosis and is as follows: (a) intact fallopian tube on the affected side, (b) fetal sac must occupy the position of the ovary on the affected side, (c) ovary connected to the uterus by ovarian ligament, (d) ovarian tissue must be located in the sac wall, confirmed by histopathology (7). Treatment of ovarian pregnancy usually requires oophorectomy or wedge resection (8) Conservative surgery in the form of ovarian wedge resection or ovarian cystectomy can be performed, if lesion is small. However, in larger lesions with active bleeding, oophorectomy should be done. Today, the surgery is often preferred laparoscopically. (8). Ovarian pregnancies have been successfully treated with methotrexate (9).

CONCLUSION: The diagnosis of ovarian ectopic pose a challenge, diagnosis is usually difficult at initial presentation. With the advent of imaging studies, diagnosis can usually be made, however the final diagnosis can be made only at the time of surgery and by histopathology. Prompt diagnosis and management is essential. Patients with an ovarian pregnancy have a good prognosis for future fertility and therefore conservative surgical management is advocated.

\section{BIBILOGRAPHY:}

1. Gaudoin MR, Coulter KL, Robins AM et al. Is the incidence of ovarian ectopic pregnancy increasing? Eur J Obstet Gynecol Reprod Biol 1996; 70:141.

2. Raziel A, Golan A, Pansky M, et al. Ovarian pregnancy: a report of twenty cases in one institution. Am J Obstet Gynecol 1990; 163:1182.

3. Borrow RC, McElin TW, West RH, Bukingham JC. Ovarian pregnancy; Report of four cases and a thirteen-year survey of the English literature. Am J Obstet Gynecol. 1965;91:1095-6

4. Comstock C, Huston K, Lee W. The ultrasonographic appearance of ovarian ectopic pregnancies. Obstet Gynecol 2005; 105:42.

5. Dart RG, Kaplan B, Varaklis K. Predictive value of history and physical examination in patients with suspected ectopic pregnancy. Ann Emerg Med 1999; 33:283.

6. Buckley RG, King KJ, Disney JD, et al. History and physical examination to estimate the risk of ectopic pregnancy: validation of a clinical prediction model. Ann Emerg Med 1999; 34:589.

7. Spiegelberg, O. Zur casvistik des ovarials schwangerschaft. Arch Gynack 1878; 13:73. 


\section{CASE REPORT}

8. Odejinmi F, Rizzuto MI, Macrae R, Olowu O, Hussain M. (2009). Diagnosis and laparoscopic management of 12 consecutive cases of ovarian pregnancy and review of literature. J Minim Invasive Gynecol.

9. Habbu J, Read MD. Ovarian pregnancy successfully treated with methotrexate. J Obstet Gynaecol 2006; 26:587.

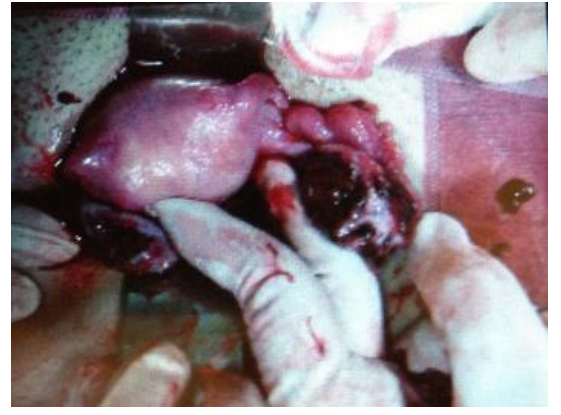

Image 1 : right ovary with gestational sac showing features of rupture.

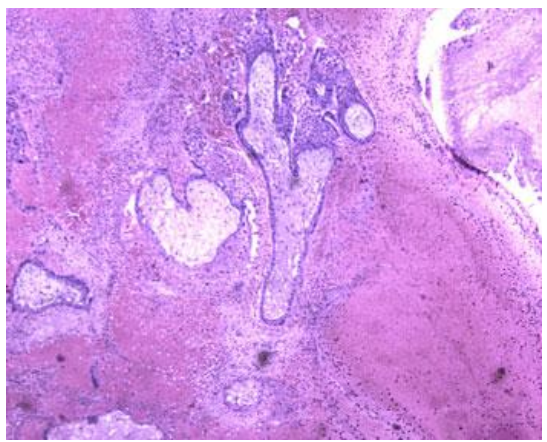

\section{AUTHORS:}

1. Irfana S.

2. Bhuvana S.

3. Jaya Vijayaraghavan

4. Sarah Kuruvilla

5. Shanmuga Priya

\section{PARTICULARS OF CONTRIBUTORS:}

1. Post Graduate, Department of Obstetrics and Gynaecology, Sri Ramchandra Medical College and Hospital.

2. Associate Professor, Department of Obstetrics and Gynaecology, Sri Ramchandra Medical College and Hospital.

3. Professor, Department of Obstetrics and Gynaecology, Sri Ramchandra Medical College and Hospital.

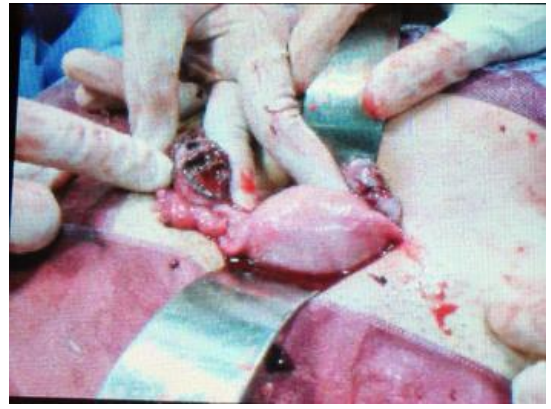

Image 2 : shows intact tubes on both sides.

Image 3 : histopathology with ovarian surface showing chorionic villi, consistent with ovarian gestation .
4. Professor, Department of Pathology, Sri Ramchandra Medical College and Hospital.

5. Assistant, Department of Pathology, Sri Ramchandra Medical College and Hospital.

\section{NAME ADDRESS EMAIL ID OF THE CORRESPONDING AUTHOR:}

Dr. Irfana $S$,

No. 87A, Anandh Bhavan, $1^{\text {st }}$ Street, AC Block, Shanthi Colony, Anna Nagar, Chennai - 600040.

Email-dr.irfana87@gmail.com

Date of Submission: 24/09/2013.

Date of Peer Review: 25/09/2013.

Date of Acceptance: 26/09/2013.

Date of Publishing: 28/09/2013. 